OPEN ACCESS

Edited by:

Fei Yin,

University of Southern California,

USA

Reviewed by:

Paula I. Moreira,

University of Coimbra

Portugal

Enrique Cadenas,

University of Southern California,

USA

*Correspondence:

Fernanda G. De Felice,

Institute of Medical Biochemistry Leopoldo de Meis, Federal University of Rio de Janeiro, Rio de Janeiro, $R J$

21941-902, Brazil

felice@biogmed.ufri.br

Received: 24 March 2015 Accepted: 04 May 2015 Published: 19 May 2015

Citation:

De Felice FG and Lourenco MV (2015) Brain metabolic stress and neuroinflammation at the basis of cognitive impairment in Alzheimer's

disease.

Front. Aging Neurosci. 7:94. doi: 10.3389/fnagi.2015.00094

\section{Brain metabolic stress and neuroinflammation at the basis of cognitive impairment in Alzheimer's disease}

\author{
Fernanda G. De Felice * and Mychael V. Lourenco \\ Institute of Medical Biochemistry Leopoldo de Meis, Federal University of Rio de Janeiro, Rio de Janeiro, RJ, Brazil
}

Brain metabolic dysfunction is known to influence brain activity in several neurological disorders, including Alzheimer's disease (AD). In fact, deregulation of neuronal metabolism has been postulated to play a key role leading to the clinical outcomes observed in AD. Besides deficits in glucose utilization in AD patients, recent evidence has implicated neuroinflammation and endoplasmic reticulum (ER) stress as components of a novel form of brain metabolic stress that develop in $A D$ and other neurological disorders. Here we review findings supporting this novel paradigm and further discuss how these mechanisms seem to participate in synapse and cognitive impairments that are germane to AD. These deleterious processes resemble pathways that act in peripheral tissues leading to insulin resistance and glucose intolerance, in an intriguing molecular connection linking $A D$ to diabetes. The discovery of detailed mechanisms leading to neuronal metabolic stress may be a key step that will allow the understanding how cognitive impairment develops in $A D$, thereby offering new avenues for effective disease prevention and therapeutic targeting.

Keywords: Alzheimer's disease, amyloid- $\beta$ oligomers, endoplasmic reticulum stress, inflammation, metabolic stress

\section{Introduction}

Incidence of Alzheimer's disease (AD) will greatly increase as world population ages (Prince et al., 2013) and changes in lifestyle observed in recent decades seem to be major contributors to such increased prevalence (Mattson, 2012; De Felice, 2013). Likewise, common diseases of modern adulthood, including obesity and diabetes mellitus, have been often regarded as AD risk factors (De Felice, 2013). Pioneering epidemiological studies connecting AD to diabetes initiated in the 1990s (Ott et al., 1996, 1999; Kalmijin et al., 1997) and were followed by several reports providing both clinical and experimental evidence into how these two disorders may course together (de la Monte, 2009; Matsuzaki et al., 2010; Crane et al., 2013; De Felice, 2013; De Felice et al., 2014).

Metabolic derangements, including inflammation, insulin resistance and endoplasmic reticulum (ER) stress, are known to underlie glucose intolerance and type 2 diabetes mellitus (T2DM) in peripheral tissues (Hotamisligil et al., 1995, 1996; Ozcan et al., 2004, 2006; Hotamisligil, 2006). A similar scenario has been recently described in the brains of patients that suffer from neurodegenerative disorders, such as AD. Neuropathology investigations have revealed that $\mathrm{AD}$ brains present several markers of insulin resistance, inflammation and ER stress (Hoozemans et al., 2005; Steen et al., 2005; Moloney et al., 2010; Bomfim et al., 2012; Talbot et al., 2012; O’Neill, 2013; 
De Felice et al., 2014). In the following sections, we review current evidence indicating that a newly defined form of metabolic stress leads the path to cognitive decline in $\mathrm{AD}$. The understanding of molecular mechanisms driving $\mathrm{AD}$ pathogenesis may shed new light on novel targets for drug development and offer strategies for disease prevention.

\section{AD Pathogenesis}

AD pathophysiology includes neuroinflammation, oxidative and ER stress, synapse loss and degeneration of specific neuronal populations (Selkoe, 2002; Ferreira and Klein, 2011; Mucke and Selkoe, 2012). Amyloid- $\beta$ peptide (A $\beta$ ) is the main component of senile plaques that accumulate in $\mathrm{AD}$ brains (Masters et al., 1985), and substantial evidence indicates that $A \beta$ is causally involved in AD (Mucke and Selkoe, 2012). Consolidated knowledge has established that soluble $A \beta$ oligomers ( $A \beta O$ s; Lambert et al., 1998), and not necessarily the insoluble amyloid fibrils detected in senile plaques, promote direct damage to synapses, besides stimulating inflammatory response and cellular stress (Ferreira and Klein, 2011; Viola and Klein, 2015). These findings prompt $\mathrm{A} \beta \mathrm{O}$, which are increased in $\mathrm{AD}$ brains (Gong et al., 2003; Xia et al., 2009), to be considered neurotoxins responsible for synapse and memory loss in $\mathrm{AD}$ early stages.

Very recent data has demonstrated that $A \beta O$ actions stimulate pro-inflammatory mechanisms to impair neuronal insulin signaling and to trigger stress kinase activation, resulting in synapse and memory impairments in AD models (Bomfim et al., 2012; Lourenco et al., 2013; Ma et al., 2013). These events are quite similar to those acting in peripheral tissues to impair metabolism in diabetes and obesity (De Felice and Ferreira, 2014), in line with the idea that a form of metabolic stress develops in AD brains (Kapogiannis and Mattson, 2011; Yoon et al., 2012; De Felice and Ferreira, 2014). Such findings may impact translational research, as treating brain metabolic dysfunction might be a key strategy to fight neurological disorders.

\section{Brain Metabolic Stress Mechanisms in AD}

In peripheral tissues, prolonged inflammatory cascades lead to the activation of multiple cellular stress mechanisms that ultimately impair cell function and body metabolism (Hotamisligil, 2006; Gregor and Hotamisligil, 2011). In AD, evidence arising from in vitro, in vivo and neuropathology studies supports that such events occur throughout disease development and are linked to $A \beta O$ neurotoxicity. Oligomers promote neuronal stress by instigating abnormal elevations in levels of tumor necrosis factor $\alpha$ (TNF- $\alpha$ ) and reactive oxygen species (ROS), as well as activation in JNK/PKR signaling and increased eIF2 $\alpha$ phosphorylation (eIF2 $\alpha-\mathrm{P}$ ) levels in AD models (De Felice et al., 2007, 2014; Ma et al., 2009, 2013; Bomfim et al., 2012; Lourenco et al., 2013). In this context, pro-inflammatory signals appear to be directly responsible for defective insulin signaling and stress-mediated synapse loss caused by ABOs in neurons (Bomfim et al., 2012; Lourenco et al., 2013). This has led to a concept in which $A \beta O$ os build up in pre-AD brains to cause inflammation (e.g., gliosis and cytokine production) and neuronal metabolic stress, ultimately leading to synaptic dysfunction and behavioral alterations. We next detail some of the mechanisms recently implicated in $\mathrm{AD}$ pathogenesis.

\section{Unfolded Protein Response}

Unfolded Protein Response (UPR) is defined as a collection of signaling pathways that respond to ER stress due to accumulation of misfolded proteins and/or impaired homeostasis. ER membrane sensors activate three signaling axes (ATF6 $\alpha$, IRE$1 \alpha /$ XBP-1s and PERK/eIF2 $\alpha-\mathrm{P}$ ) to instigate transcriptional and translational alterations aimed at restoring cell homeostasis (Lai et al., 2007; Hetz et al., 2013). UPR signaling attenuates global translation and favors the synthesis of select transcription factors, such as ATF4, CHOP and Nrf2 (Buffington et al., 2014; Hetz and Mollereau, 2014). Under continued stress, however, these pathways may promote cell damage and death. This hormetic response pattern is thus critical to determine cell fate in such conditions (Mattson, 2008; Hetz, 2012).

Evidence for canonical UPR activation has been found in AD neurons (Hoozemans et al., 2005, 2009; Yoon et al., 2012) and in AD mouse models (Yoon et al., 2012; Ma et al., 2013). In accordance, $\mathrm{A} \beta \mathrm{O}$ s trigger UPR in hippocampal neurons in vitro and in vivo (Chafekar et al., 2007; Casas-Tinto et al., 2011; Lourenco et al., 2013; Barbero-Camps et al., 2014), and experimental induction of ER stress leads to neuronal metabolic stress (Yoon et al., 2012), tau phosphorylation (Bose et al., 2011; van der Harg et al., 2014), stress kinase activation (Bose et al., 2011; Paquet et al., 2011) and cognitive impairment in mice (Lourenco et al., 2013). Further, alleviating ER stress with 4-phenylbutyrate, a chemical chaperone, promotes cognitive benefits in AD mouse models (Ricobaraza et al., 2009, 2010; Wiley et al., 2011; Lourenco et al., 2013).

Substantial recent evidence has proposed that UPR activation is a common feature of different neurodegenerative diseases, as deleterious impacts of UPR branches were reported in $\mathrm{AD}$ (Lourenco et al., 2013; Ma et al., 2013; Barbero-Camps et al., 2014; van der Harg et al., 2014), Parkinson's (Bellucci et al., 2011; Colla et al., 2012), Huntington (Lajole and Snapp, 2011), amyotrophic lateral sclerosis (ALS; Hetz et al., 2009; Kim et al., 2013) and prion diseases (Moreno et al., 2012). Correcting UPR activation further appears to be effective in preclinical models of prion infection (Moreno et al., 2012, 2013; Halliday et al., 2015) and ALS (Hetz et al., 2009; Kim et al., 2013), in addition to AD models (Ricobaraza et al., 2009, 2010; Lourenco et al., 2013; Ma et al., 2013). Therefore, it is likely that aberrant UPR signaling mediates brain dysfunction in a variety of neurological conditions (Figure 1).

\section{elF2 $\alpha-P$ and Translational Repression}

Under cellular stress, translational repression can be mediated by increased eIF $2 \alpha$ phosphorylation (eIF2 $\alpha-P$ ), a regulatory factor essential for translation initiation in eukaryotes (Raven and Koromilas, 2008). PERK-mediated eIF2 $\alpha-\mathrm{P}$ is the main UPR branch leading to general protein synthesis repression and 


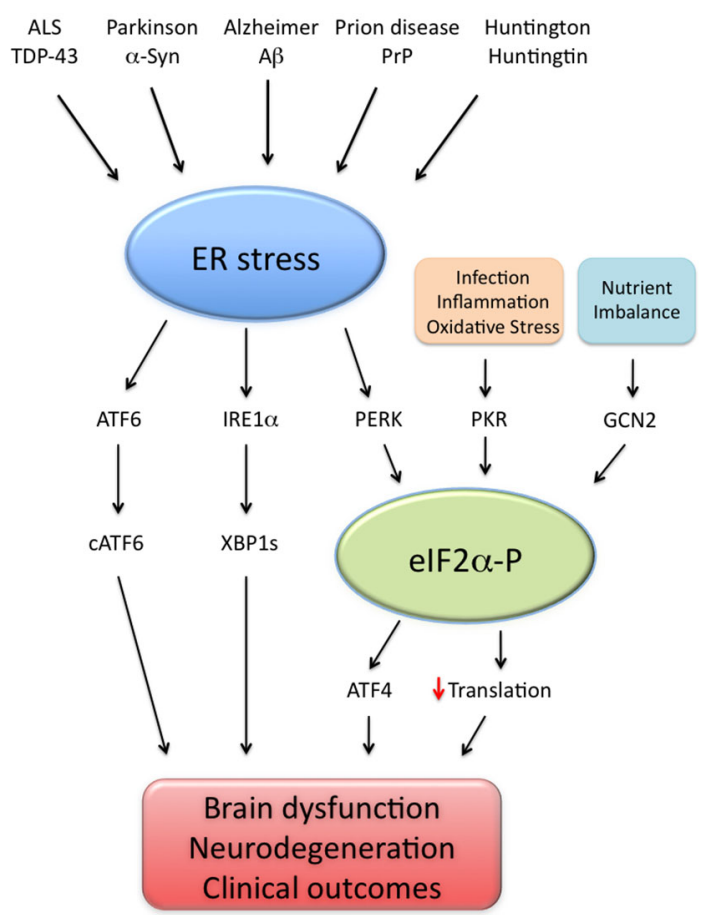

FIGURE 1 | Endoplasmic reticulum (ER) stress as a common denominator of neurodegenerative diseases. Brain ER stress is caused by several disease-associated stressors, including amyloid- $\beta$ (A $\beta$; Alzheimer disease), $\alpha$-synuclein ( $\alpha$-syn; Parkinson disease), prion protein (PrP; prion-related diseases), mutated huntingtin (Huntington and poly-Q diseases) and TAR DNA-binding protein of $43 \mathrm{kDa}$ (TDP-43; amyotrophic lateral sclerosis, ALS). In such disorders, abnormal ER stress leads to the activation of three signaling pathways (ATF6; IRE1 $\alpha /$ XBP1 s and PERK/elF2 $\alpha-P$ ) collectively termed unfolded protein response (UPR). In parallel, events of infection, inflammation, nutrient deprivation and oxidative stress activate additional elF2 $\alpha$ kinases (namely PKR and GCN2), leading to abnormally high elF2 $\alpha$-P levels, increased ATF4 production and impaired translation. Excessive UPR activity, elF2 $\alpha-P$ signaling and their downstream effectors impair cell function and may result in brain dysfunction and neurodegeneration, possibly explaining the clinical outcomes observed in neurodegenerative conditions.

facilitation of select mRNA translation (Buffington et al., 2014). Both PERK and eIF2 $\alpha$-P appear to be elevated in AD brains (Chang et al., 2002b; Yoon et al., 2012; Ma et al., 2013) and are induced by $A \beta$ aggregates in neurons (Lee et al., 2010). Increased eIF $2 \alpha-P$ has been further verified in other AD mouse models (Segev et al., 2012; Devi and Ohno, 2014).

Two other eIF2 $\alpha$ kinases, namely the stress kinase PKR and the nutrient sensor GCN2, are enriched in the brain and have been reported to increase neuronal eIF $2 \alpha-\mathrm{P}$ (Costa-Mattioli et al., 2005; Lourenco et al., 2013; Roffé et al., 2013; Hetz and Mollereau, 2014), and thus emerge as candidates to explain increased eIF2 $\alpha$ $\mathrm{P}$ in $\mathrm{AD}$.

Interestingly, deletion of either PERK or GCN2 in the brains of APP/PS1 mice decreases eIF2 $\alpha$-P levels, rescuing synapse plasticity and cognition (Ma et al., 2013). A $\beta$ Os increase eIF2 $\alpha$ $P$ through TNF- $\alpha$-dependent PKR activation, thereby promoting synapse loss in hippocampal neurons and cognitive impairment in mice (Paquet et al., 2011; Lourenco et al., 2013). Providing clinical relevance to the findings observed in experimental models, PKR was found to be abnormally active in AD brains (Chang et al., 2002a; Paquet et al., 2011; Mouton-Liger et al., 2012b). Therefore, it is likely that PERK, GCN2, and PKR lead to increased eIF $2 \alpha-\mathrm{P}$ levels in AD.

Increased eIF $2 \alpha-\mathrm{P}$ levels also facilitate the translation of a small fraction of mRNAs (Buffington et al., 2014), among which is activating transcription factor 4 (ATF4), a protein linked to oxidative stress, enhanced $\gamma$-secretase activity and neuronal dysfunction when abnormally elevated (Mitsuda et al., 2007; Lange et al., 2008). ATF4 signaling further counteracts CREB1 pro-memory actions in mice (Costa-Mattioli et al., 2005; Rajasethupathy et al., 2012).

Recent findings demonstrated that ATF4 levels are increased in AD brains (Yoon et al., 2012; Baleriola et al., 2014) and in AD animal models (Ma et al., 2013; Devi and Ohno, 2014). Furthermore, soluble $\mathrm{A} \beta$ species appear to locally stimulate axonal ATF4 translation to propagate a neurodegenerative message in mice (Baleriola et al., 2014). Hence, eIF2 $\alpha$-P/ATF4 signaling has the potential to explain, at least in part, how disease progresses from defined brain regions in the beginning to a widespread forebrain dysfunction at later stages.

Translational repression instigated by eIF $2 \alpha-\mathrm{P}$ may be harmful to cognition, given that normal protein synthesis is required for memory (Flexner et al., 1964; Rossato et al., 2007). Accordingly, APP/PS1 mice present reduced brain protein synthesis in parallel to memory loss, and A $\beta$ Os impair LTPinduced hippocampal protein synthesis (Ma et al., 2013). Nevertheless, the identity of memory-relevant translational products that are impacted in $\mathrm{AD}$ still remains to be determined.

\section{Stress Kinase Activation}

Cellular stress is also known to activate a family of protein kinases that mediate adaptive responses (Calay and Hotamisligil, 2013). These proteins are termed stress-sensitive kinases (or simply stress kinases) and include JNK, p38 MAPK, PKR, PERK and IKK, among other serine/threonine kinases (Vallerie and Hotamisligil, 2010; Hetz and Mollereau, 2014). Active stress kinases phosphorylate several protein targets to restore homeostasis. Nevertheless, their excessive or prolonged actions may trigger cell injury and, later, programmed cell death (Mattson, 2008; Vallerie and Hotamisligil, 2010; Hetz, 2012; De Felice et al., 2014).

Neuropathology studies have demonstrated abnormal activation of neuronal stress-sensitive kinases in $\mathrm{AD}$ brains. Indeed, abnormal phosphorylation of p38 MAPK (Hensley et al., 1999), JNK (Ma et al., 2009; Bomfim et al., 2012; Yoon et al., 2012), PERK (Hoozemans et al., 2005, 2009), PKR (Chang et al., 2002a; Paquet et al., 2011) and IKK (Talbot et al., 2012) have been reported in $\mathrm{AD}$ brains and might be core mediators of neuronal dysfunction. Accordingly, A $\beta O$ s have been described to activate neuronal JNK and PKR to impair insulin signaling and synapse function (Ma et al., 2009; Bomfim et al., 2012; Lourenco et al., 2013), and transgenic animal models of AD exhibit similar alterations in JNK and PKR activity (Ma et al., 2009; Bomfim et al., 2012; Lourenco et al., 2013). Consistently, 
blocking either PKR or the brain-enriched JNK3 rescue cognitive impairments in AD mouse models (Yoon et al., 2012; Lourenco et al., 2013), suggesting that stress kinase activation lies upstream of synapse and memory impairment in $\mathrm{AD}$.

An attractive possibility is that PKR further drives the activation of other MAPKs, such as P38MAPK and JNK, thus exacerbating neuronal damage. Very recent findings suggest that the interaction between PKR and the RNA-binding protein TRBP is essential to promote eIF $2 \alpha-\mathrm{P}$ and JNK activation under obesity-induced metabolic stress (Nakamura et al., 2015). A similar scenario might also develop in AD even independently of TNF- $\alpha$, given that oxidative stress has been reported to activate neuronal PKR (Mouton-Liger et al., 2012a). Moreover, $A \beta O$ s could activate PKR in glial cells to instigate MAPK-dependent actions, exacerbating neuroinflammatory responses in $\mathrm{AD}$ brains. These notions still demand further investigation.

\section{Neuroinflammation}

Elevated markers of inflammation are found in both $\mathrm{AD}$ animal models and human AD brains (Ferreira et al., 2014; Monson et al., 2014; Heneka et al., 2015). Consistently, evidence for gliosis and central infiltration of peripheral immune cells is often found in histopathological studies in AD mouse models (Yamanaka et al., 2012; Lourenco and Ledo, 2013; Yang et al., 2013; Baik et al., 2014; Ferreira et al., 2014; Monson et al., 2014).

Amyloid aggregates (ranging from oligomers to fibrils) induce a neuroinflammatory profile that may lead to synapse and neuronal damage (Combs, 2009; Pan et al., 2011; Lourenco et al., 2013; Medinas and Hetz, 2013; Parajuli et al., 2013; Heneka et al., 2015). Nevertheless, rather than deposited plaques, $\mathrm{A} \beta \mathrm{O}$ s are thought to be core inducers of brain inflammation, given that they are potent microglial activators (Floden and Combs, 2006; Dhawan et al., 2012; Ledo et al., 2013) and diffuse throughout brain regions (Lambert et al., 1998; Forny-Germano et al., 2014; Viola and Klein, 2015). Accumulating evidence suggests that $\mathrm{A} \beta \mathrm{O}-$ induced microglial activation releases TNF- $\alpha$ and other cytokines that, in turn, act on neurons to cause stress signaling and synapse injury (Floden and Combs, 2006; Sondag et al., 2009; Bomfim et al., 2012; Dhawan et al., 2012; Lourenco et al., 2013).

Therefore, neuroinflammation is considered to take place over the degenerative course of $\mathrm{AD}$ and to be linked to cognitive dysfunction. In fact, our recent results showed that A $\beta O$-triggered elevations in TNF- $\alpha$ levels orchestrate neuronal stress mechanisms to impair brain insulin signaling (Bomfim et al., 2012), synapses and cognition in animal models of $\mathrm{AD}$ (Lourenco et al., 2013; Figure 2). This cascade is mediated by stress kinases, including JNK and PKR, in the brains affected by A $\beta O$ s (Lourenco et al., 2013). Since evidence suggests that reducing neuroinflammation can counteract memory deficits in AD mouse models (Medeiros et al., 2007; McAlpine et al., 2009; Kiyota et al., 2010; Bachstetter et al., 2012), a more complete understanding of how brain inflammation develops may lead to effective targeting of aberrant mechanisms underlying cognitive symptoms in $\mathrm{AD}$.

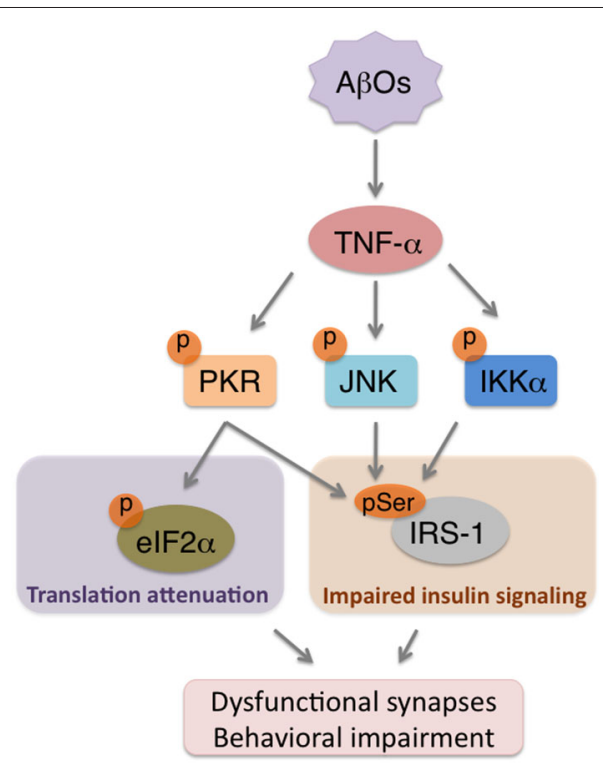

FIGURE 2 | A $\beta$ Os trigger brain metabolic stress in Alzheimer's Disease (AD). Accumulation of $A \beta O$ s in pre-AD brains instigates an inflammatory response that involves increased TNF- $\alpha$ production. TNF- $\alpha$, in turn, acts on neurons to promote the activity of stress kinases (e.g., PKR, JNK, IKK $\alpha$ ), which will serine phosphorylate both elF2 $\alpha-\mathrm{P}$ to attenuate translation, and IRS-1 to impair insulin signaling. The combination of repressed protein synthesis and defective insulin signaling are components of a novel form of neuronal metabolic stress that may contribute to synapse deregulation and cognitive impairment in AD.

\section{Metabolic Stress and Cognitive Function in AD}

Experimental evidence has gathered inflammation, defective insulin signaling and cell stress to AD-linked neurotoxicity and neurodegeneration in a revised concept of metabolic stress (Paquet et al., 2011; Mouton-Liger et al., 2012a; Yoon et al., 2012; Ledo et al., 2013; Lourenco et al., 2013; Ma et al., 2013; Baleriola et al., 2014; De Felice et al., 2014). Although the classical alterations in glucose metabolism germane to metabolic impairments are observed in AD brains (Hoyer et al., 1988; Kapogiannis and Mattson, 2011; Chen and Zhong, 2013), the modern notion of metabolic stress also includes disturbances in proteostasis and activation of signaling pathways that mediate cellular stress.

In this context, the progressive build-up of $\mathrm{A} \beta \mathrm{O}$ s in $\mathrm{AD}$ brains might trigger the activation of immune mechanisms, including glial cell reactivity and cytokine release that, in turn, lead to neuronal metabolic stress. A point of convergence of multiple stress pathways is found on elevated eIF $2 \alpha$-P levels. Accordingly, PKR, ER stress, eIF2 $\alpha-\mathrm{P}$ and ATF4 have been described as negative modulators of memory (Costa-Mattioli et al., 2007; Zhu et al., 2011; Rajasethupathy et al., 2012; Lourenco et al., 2013; Stern et al., 2013; Di Prisco et al., 2014; Ounallah-Saad et al., 2014). By acting together, such pathways might disrupt brain homeostasis and contribute to the cognitive decline observed in $\mathrm{AD}$. 
The precise mechanisms linking metabolic stress to synapse defects are still not fully understood, but the findings that increased eIF2 $\alpha$-P levels lead to LTP impairments (Ma et al., 2013) and synapse loss (Lourenco et al., 2013) in mice have provided initial clues on this causal relationship. Consistently, restoring normal brain eIF $2 \alpha-\mathrm{P}$ levels was shown to abrogate deficient levels of synaptic proteins and cognition (Lourenco et al., 2013; Ma et al., 2013), indicating a tight connection between eIF2 $\alpha-\mathrm{P}$ and synapse/memory integrity.

It is noteworthy that activation of PKR/eIF $2 \alpha-\mathrm{P}$ signaling (O'Connor et al., 2008; Devi and Ohno, 2010; Mouton-Liger et al., 2012a), as well as high-fat diet-induced metabolic stress (Wang et al., 2013) was shown to promote amyloidogenesis in a feed-forward cycle that might exacerbate amyloid pathology. It is thus tempting to speculate that accumulating injuries throughout life, including infections, diabetes and obesity, could instigate a brain metabolic stress scenario that includes ER stress and neuroinflammation to facilitate $A \beta$ accumulation and sporadic AD onset at later stages of life (Herrup, 2010; Mattson, 2012; De Felice, 2013).

An unresolved question relates to whether brain insulin resistance could itself trigger $\mathrm{AD}$-related phenomena, even in the absence of inflammation. In this regard, early studies using neuronal insulin receptor knockout (NIRKO) mice found that deficient brain insulin signaling causes abnormal tau phosphorylation without spatial memory impairment (Schubert et al., 2004). Recently, NIRKO mice were shown to develop anxiety and depressive-like behavior linked to altered dopamine metabolism (Kleinridders et al., 2015), and deletion of a single gene copy that encodes an insulin receptor subunit in the brain impairs synaptic plasticity and cognition (Nisticò et al., 2012). Nonetheless, it remains to be determined whether such mice develop brain metabolic stress in the presence or absence of neurotoxic stimuli. Future investigation may dissect the molecular steps that are required for metabolic stress-induced synapse impairments in an $\mathrm{AD}$ context.

\section{Conclusions}

Recent exciting evidence has connected A $\beta O$-induced neuronal stress to cognitive impairments in $\mathrm{AD}$, in a mechanism

\section{References}

Bachstetter, A. D., Norris, C. M., Sompol, P., Wilcock, D. M., Goulding, D., Neltner, J. H., et al. (2012). Early stage drug treatment that normalizes proinflammatory cytokine production attenuates synaptic dysfunction in a mouse model that exhibits age-dependent progression of Alzheimer's diseaserelated pathology. J. Neurosci. 32, 10201-10210. doi: 10.1523/jneurosci.149612.2012

Baik, S. H., Cha, M. Y., Hyun, Y. M., Cho, H., Hamza, B., Kim, D. K., et al. (2014). Migration of neutrophils targeting amyloid plaques in Alzheimer's disease mouse model. Neurobiol. Aging 35, 1286-1292. doi: 10.1016/j.neurobiolaging. 2014.01.003

Baleriola, J., Walker, C. A., Jean, Y. Y., Crary, J. F., Troy, C. M., Nagy, P. L., et al. (2014). Axonally synthesized ATF4 transmits a neurodegenerative signal across brain regions. Cell 158, 1159-1172. doi: 10.1016/j.cell.2014.07.001

Barbero-Camps, E., Fernández, A., Baulies, A., Martinez, L., Fernández-Checa, J. C., and Colell, A. (2014). Endoplasmic reticulum stress mediates amyloid that includes cytokine-induced activation of stress kinases and ultimately leads to neuronal and synapse dysfunction in $\mathrm{AD}$ experimental models (De Felice et al., 2007; Yoon et al., 2012; De Felice, 2013; Lourenco et al., 2013; Ma et al., 2013; Baleriola et al., 2014; De Felice and Ferreira, 2014; Ferreira et al., 2014). Hence, the combination of inflammation, neuronal insulin resistance, oxidative/ER stress and translational repression might generate a noxious scenario of brain metabolic stress to mediate and propagate synapse defects, resulting in cognitive deficits. In this context, ER stress and abnormal eIF2 $\alpha$-P levels emerged as key players in neuronal damage.

Sporadic AD is largely idiopathic, and it is noteworthy that $\mathrm{A} \beta$-centric views of $\mathrm{AD}$ pathogenesis remain controversial (see Morris et al., 2014 for a critical review). Nonetheless, recent progress summarized here may have deep implications for disease prevention, as avoiding harmful events throughout life might reduce the risk of brain inflammation, metabolic stress and, consequently, of developing $\mathrm{AD}$ at later stages of life. Interrupting deleterious molecular pathways at prodromal stages will likely be the ideal strategy to delay $\mathrm{AD}$ progression. The identification of common $\mathrm{AD}$ drivers is imperative to establish effective therapeutics, and blocking neuronal metabolic stress at the earliest cognitive symptoms could offer a promising approach to minimize neuronal dysfunction and AD progression. Repurposing labeled antidiabetic compounds could constitute an interesting option as they have been shown to attenuate $\mathrm{AD}$-linked brain metabolic stress and memory dysfunction (Craft, 2012; De Felice et al., 2014). Future clinical trials may reveal whether these drugs, alone or in combination, are indeed effective in $\mathrm{AD}$.

\section{Acknowledgments}

Work in De Felice lab has been supported by grants from Conselho Nacional de Desenvolvimento Científico e Tecnológico (CNPq), Fundação de Amparo à Pesquisa do Estado do Rio de Janeiro (FAPERJ) and Human Frontier Science Program (HFSP). MVL is supported by a CNPq predoctoral scholarship.

beta neurotoxicity via mitochondrial cholesterol trafficking. Am. J. Pathol. 184, 2066-2081. doi: 10.1016/j.ajpath.2014.03.014

Bellucci, A., Navarria, L., Zaltieri, M., Falarti, E., Bodei, S., Sigala, S., et al. (2011) Induction of the unfolded protein response by alpha-synuclein in experimental models of Parkinson's disease. J. Neurochem. 116, 588-605. doi: 10.1111/j.14714159.2010.07143.x

Bomfim, T. R., Forny-Germano, L., Sathler, L. B., Brito-Moreira, J., Houzel, J. C., Decker, H., et al. (2012). An anti-diabetes agent protects the mouse brain from defective insulin signaling caused by Alzheimer's disease-associated A $\beta$ oligomers. J. Clin. Invest. 122, 1339-1353. doi: 10.1172/jci57256

Bose, A., Mouton-Liger, F., Paquet, C., Mazot, P., Vigny, M., Gray, F., et al. (2011). Modulation of tau phosphorylation by the kinase PKR: implications in Alzheimer's disease. Brain Pathol. 21, 189-200. doi: 10.1111/j.1750-3639.2010. 00437.x

Buffington, S. A., Huang, W., and Costa-Mattioli, M. (2014). Translational control in synaptic plasticity and cognitive dysfunction. Annu. Rev. Neurosci. 37, 17-38. doi: 10.1146/annurev-neuro-071013-014100 
Calay, E. S., and Hotamisligil, G. S. (2013). Turning off the inflammatory, but not the metabolic, flames. Nat. Med. 19, 265-267. doi: 10.1038/nm.3114

Casas-Tinto, S., Zhang, Y., Sanchez-Garcia, J., Gomez-Velazquez, M., RinconLimas, D. E., and Fernandez-Funez, P. (2011). The ER stress factor XBP1s prevents amyloid- neurotoxicity. Hum. Mol. Genet. 20, 2144-2160. doi: 10. 1093/hmg/ddr100

Chafekar, S. M., Hoozemans, J. J. M., Zwart, R., Baas, F., and Scheper, W. (2007). A $\beta 1-42$ induces mild endoplasmic reticulum stress in an aggregation State-dependent manner. Antioxid. Redox Signal. 9, 2245-2254. doi: 10. 1089/ars.2007.1797

Chang, R., Suen, K.-C., Ma, C.-H., Elyaman, W., Ng, H.-K., and Hugon, J. (2002a). Involvement of double-stranded RNA-dependent protein kinase and phosphorylation of eukaryotic initiation factor-2alpha in neuronal degeneration. J. Neurochem. 83, 1215-1225. doi: 10.1046/j.1471-4159.2002. 01237.x

Chang, R. C., Wong, A. K., Ng, H. K., and Hugon, J. (2002b). Phosphorylation of eukaryotic initiation factor 2 alpha (eIF2alpha) is associated with neuronal degeneration in Alzheimer's disease. Neuroreport 13, 2429-2432. doi: 10. 1097/00001756-200212200-00011

Chen, Z., and Zhong, C. (2013). Decoding Alzheimer's disease from perturbed cerebral glucose metabolism: implications for diagnostic and therapeutic strategies. Prog. Neurobiol. 108, 21-43. doi: 10.1016/j.pneurobio.2013. 06.004

Colla, E., Coune, P., Liu, Y., Pletnikova, O., Troncoso, J. C., Iwatsubo, T., et al. (2012). Endoplasmic reticulum stress is important for the manifestations of $\alpha$-synucleinopathy in vivo. J. Neurosci. 32, 3306-3320. doi: 10.1523/jneurosci. $5367-11.2012$

Combs, C. K. (2009). Inflammation and microglia actions in Alzheimer's disease. J. Neuroimmune Pharmacol. 4, 380-388. doi: 10.1007/s11481-0099165-3

Costa-Mattioli, M., Gobert, D., Harding, H., Herdy, B., Azzi, M., Bruno, M., et al. (2005). Translational control of hippocampal synaptic plasticity and memory by the eIF2alpha kinase GCN2. Nature 436, 1166-1173. doi: 10 . 1038/nature03897

Costa-Mattioli, M., Gobert, D., Stern, E., Gamache, K., Colina, R., Cuello, C., et al. (2007). eIF $2 \alpha$ phosphorylation bidirectionally regulates the switch from shortto long-term synaptic plasticity and memory. Cell 129, 195-206. doi: 10.1016/j. cell.2007.01.050

Craft, S. (2012). Alzheimer disease: insulin resistance and AD-extending the translational path. Nat. Rev. Neurol. 8, 360-362. doi: 10.1038/nrneurol. 2012.112

Crane, P. K., Walker, R., Hubbard, R. A., Li, G., Nathan, D. M., Zheng, H., et al. (2013). Glucose levels and risk of dementia. N. Engl. J. Med. 369, 540-548. doi: 10.1056/NEJMoa1215740

De Felice, F. G. (2013). Alzheimer's disease and insulin resistance: translating basic science into clinical applications. J. Clin. Invest. 123, 531-539. doi: 10. 1172/JCI64595

De Felice, F. G., and Ferreira, S. T. (2014). Inflammation, defective insulin signaling and mitochondrial dysfunction as common molecular denominators connecting type 2 diabetes to Alzheimer disease. Diabetes 63, 2262-2272. doi: $10.2337 / \mathrm{db} 13-1954$

De Felice, F. G., Lourenco, M. V., and Ferreira, S. T. (2014). How does brain insulin resistance develop in Alzheimer's disease? Alzheimers Dement. 10, S26-S32. doi: 10.1016/j.jalz.2013.12.004

De Felice, F. G., Velasco, P. T., Lambert, M. P., Viola, K., Fernandez, S. J., Ferreira, S. T., et al. (2007). A $\beta$ oligomers induce neuronal oxidative stress through an $\mathrm{N}$-methyl-D-aspartate receptor-dependent mechanism that is blocked by the Alzheimer drug memantine. J. Biol. Chem. 282, 11590-11601. doi: 10.1074/jbc. m607483200

de la Monte, S. (2009). Insulin resistance and Alzheimer's disease. BMB Rep. 42, 475-481. doi: 10.5483/BMBRep.2009.42.8.475

Devi, L., and Ohno, M. (2010). Phospho-eIF2alpha level is important for determining abilities of BACE1 reduction to rescue cholinergic neurodegeneration and memory defects in 5XFAD mice. PLoS One 5:e12974. doi: 10.1371/journal.pone.0012974

Devi, L., and Ohno, M. (2014). PERK mediates eIF2alpha phosphorylation responsible for BACE1 elevation, CREB dysfunction and neurodegeneration in a mouse model of Alzheimer's disease. Neurobiol. Aging 35, 2272-2281. doi: 10. 1016/j.neurobiolaging.2014.04.031
Dhawan, G., Floden, A. M., and Combs, C. K. (2012). Amyloid- $\beta$ oligomers stimulate microglia through a tyrosine kinase mechanism. Neurobiol. Aging 33, 2247-2261. doi: 10.1016/j.neurobiolaging.2011.10.027

Di Prisco, G. V., Huang, W., Buffington, S. A., Hsu, C. C., Bonnen, P. E., Placzek, A. N., et al. (2014). Translational control of mGluR-dependent longterm depression and object-place learning by eIF2alpha. Nat. Neurosci. 17, 1073-1082. doi: 10.1038/nn.3754

Ferreira, S. T., Clarke, J. R., Bomfim, T. R., and De Felice, F. G. (2014). Inflammation, defective insulin signaling and neuronal dysfunction in Alzheimer's disease. Alzheimers Dement. 10(1 Suppl), S76-S83. doi: 10.1016/ j.jalz.2013.12.010

Ferreira, S. T., and Klein, W. L. (2011). The A $\beta$ oligomer hypothesis for synapse failure and memory loss in Alzheimer's disease. Neurobiol. Learn. Mem. 96, 529-543. doi: 10.1016/j.nlm.2011.08.003

Flexner, L. B., Flexner, J. B., Roberts, R. B., and De La Haba, G. (1964). Loss of recent memory in mice as related to regional inhibition of cerebral protein synthesis. Proc. Natl. Acad. Sci. U S A 52, 1165-1169. doi: 10.1073/pnas.52. 5.1165

Floden, A. M., and Combs, C. K. (2006). Beta-amyloid stimulates murine postnatal and adult microglia cultures in a unique manner. J. Neurosci. 26, 4644-4648. doi: 10.1523/jneurosci.4822-05.2006

Forny-Germano, L., Lyra E Silva, N. M., Batista, A. F., Brito-Moreira, J., Gralle, M., Boehnke, S. E., et al. (2014). Alzheimer's disease-like pathology induced by amyloid-beta oligomers in nonhuman primates. J. Neurosci. 34, 13629-13643. doi: 10.1523/JNEUROSCI.1353-14.2014

Gong, Y., Chang, L., Viola, K. L., Lacor, P. N., Lambert, M. P., Finch, C. E., et al. (2003). Alzheimer's disease-affected brain: presence of oligomeric $\mathrm{A} \beta$ ligands (ADDLs) suggests a molecular basis for reversible memory loss. Proc. Natl. Acad. Sci. U S A 100, 10417-10422. doi: 10.1073/pnas. 1834302100

Gregor, M. F., and Hotamisligil, G. S. (2011). Inflammatory mechanisms in obesity. Annu. Rev. Immunol. 29, 415-445. doi: 10.1146/annurev-immunol031210-101322

Halliday, M., Radford, H., Sekine, Y., Moreno, J., Verity, N., Le Quesne, J., et al. (2015). Partial restoration of protein synthesis rates by the small molecule ISRIB prevents neurodegeneration without pancreatic toxicity. Cell Death Dis. 6:e1672. doi: 10.1038/cddis.2015.49

Heneka, M. T., Golenbock, D. T., and Latz, E. (2015). Innate immunity in Alzheimer's disease. Nat. Immunol. 16, 229-236. doi: 10.1038/ni.3102

Hensley, K., Floyd, R. A., Zheng, N.-Y., Nael, R., Robinson, K. A., Nguyen, X., et al. (1999). p38 kinase is activated in the Alzheimer's disease brain. J. Neurochem. 72, 2053-2058. doi: 10.1046/j.1471-4159.1999.0722053.x

Herrup, K. (2010). Reimagining Alzheimer's disease-an age-based hypothesis. J. Neurosci. 30, 16755-16762. doi: 10.1523/JNEUROSCI.4521-10.2010

Hetz, C. (2012). The unfolded protein response: controlling cell fate decisions under ER stress and beyond. Nat. Rev. Mol. Cell Biol. 13, 89-102. doi: 10. 1038/nrm3270

Hetz, C., Chevet, E., and Harding, H. P. (2013). Targeting the unfolded protein response in disease. Nat. Rev. Drug Discov. 12, 703-719. doi: 10.1038/nrd3976

Hetz, C., and Mollereau, B. (2014). Disturbance of endoplasmic reticulum proteostasis in neurodegenerative diseases. Nat. Rev. Neurosci. 15, 233-249. doi: $10.1038 / \mathrm{nrn} 3689$

Hetz, C., Thielen, P., Matus, S., Nassif, M., Court, F., Kiffin, R., et al. (2009). XBP-1 deficiency in the nervous system protects against amyotrophic lateral sclerosis by increasing autophagy. Genes Dev. 23, 2294-2306. doi: 10.1101/gad.18 30709

Hoozemans, J. J. M., Van Haastert, E. S., Nijholt, D. A. T., Rozemuller, A. J. M., Eikelenboom, P., and Scheper, W. (2009). The unfolded protein response is activated in pretangle neurons in Alzheimer's disease hippocampus. Am. J. Pathol. 174, 1241-1251. doi: 10.2353/ajpath.2009.080814

Hoozemans, J. J. M., Veerhuis, R., Haastert, E. S., Rozemuller, J. M., Baas, F., Eikelenboom, P., et al. (2005). The unfolded protein response is activated in Alzheimer's disease. Acta Neuropathol. 110, 165-172. doi: 10.1007/s00401-0051038-0

Hotamisligil, G. S. (2006). Inflammation and metabolic disorders. Nature 444, 860-867. doi: 10.1038/nature05485

Hotamisligil, G. S., Arner, P., Caro, J. F., Atkinson, R. L., and Spiegelman, B. M. (1995). Increased adipose tissue expression of tumor necrosis factor-a in human obesity and insulin resistance. J. Clin. Invest. 95, 2409-2415. doi: 10. $1172 /$ jci117936 
Hotamisligil, G. S., Peraldi, P., Budavari, A., Ellis, R., White, M. F., and Spiegelman, B. M. (1996). IRS-1-mediated inhibition of insulin receptor tyrosine kinase activity in TNF- $\alpha$ - and obesity-induced insulin resistance. Science 271, 665-668. doi: 10.1126/science.271.5249.665

Hoyer, S., Oesterreich, K., and Wagner, O. (1988). Glucose metabolism as the site of the primary abnormality in early-onset dementia of Alzheimer type? J. Neurol. 235, 143-148. doi: 10.1007/bf00314304

Kalmijin, S., Launer, L. J., Ott, A., Witteman, J. C., Hofman, A., and Breteler, M. M. (1997). Dietary fat intake and the risk of incident dementia in the Rotterdam study. Ann. Neurol. 42, 776-782. doi: 10.1002/ana.410420514

Kapogiannis, D., and Mattson, M. P. (2011). Disrupted energy metabolism and neuronal circuit dysfunction in cognitive impairment and Alzheimer's disease. Lancet Neurol. 10, 187-198. doi: 10.1016/S1474-4422(10)70277-5

Kim, H.-J., Raphael, A. R., Ladow, E. S., Mcgurk, L., Weber, R. A., Trojanowski, J. Q., et al. (2013). Therapeutic modulation of eIF $2 \alpha$ phosphorylation rescues TDP-43 toxicity in amyotrophic lateral sclerosis disease models. Nat. Genet. 46, 152-160. doi: 10.1038/ng.2853

Kiyota, T., Okuyama, S., Swan, R. J., Jacobsen, M. T., Gendelman, H. E., and Ikezu, T. (2010). CNS expression of anti-inflammatory cytokine interleukin4 attenuates Alzheimer's disease-like pathogenesis in APP+PS1 bigenic mice. FASEB J. 24, 3093-3102. doi: 10.1096/fj.10-155317

Kleinridders, A., Cai, W., Cappellucci, L., Ghazarian, A., Collins, W. R., Vienberg, S. G., et al. (2015). Insulin resistance in brain alters dopamine turnover and causes behavioral disorders. Proc. Natl. Acad. Sci. US A 112, 3463-3468. doi: 10. 1073/pnas. 1500877112

Lai, E., Teodoro, T., and Volchuk, A. (2007). Endoplasmic reticulum stress: signaling the unfolded protein response. Physiology (Bethesda) 22, 193-201. doi: 10.1152/physiol.00050.2006

Lajole, P., and Snapp, E. L. (2011). Changes in BiP availability reveal hypersensitivity to acute endoplasmic reticulum stress in cells expressing mutant huntingtin. J. Cell Sci. 124, 3332-3343. doi: 10.1242/jcs.087510

Lambert, M. P., Barlow, A. K., Chromy, B. A., Edwards, C., Freed, R., Liosatos, M., et al. (1998). Diffusible, nonfibrillar ligands derived from Abeta1-42 are potent central nervous system neurotoxins. Proc. Natl. Acad. Sci. U S A 95, 6448-6453. doi: 10.1073/pnas.95.11.6448

Lange, P. S., Chavez, J. C., Pinto, J. T., Coppola, G., Sun, C. W., Townes, T. M., et al. (2008). ATF4 is an oxidative stress-inducible, prodeath transcription factor in neurons in vitro and in vivo. J. Exp. Med. 205, 1227-1242. doi: 10.1084/jem. 20071460

Ledo, J. H., Azevedo, E. P., Clarke, J. R., Ribeiro, F. C., Figueiredo, C. P., Foguel, D., et al. (2013). Amyloid- $\beta$ oligomers link depressive-like behavior and cognitive deficits in mice. Mol. Psychiatry 18, 1053-1054. doi: 10.1038/mp. 2012.168

Lee, D. Y., Lee, K.-S., Lee, H. J., Kim, D. H., Noh, Y. H., Yu, K., et al. (2010). Activation of PERK signaling attenuates Abeta-mediated ER stress. PloS One 5:e10489. doi: 10.1371/journal.pone.0010489

Lourenco, M. V., Clarke, J. R., Frozza, R. L., Bomfim, T. R., Forny-Germano, L., Batista, A. F., et al. (2013). TNF- $\alpha$ mediates PKR-dependent memory impairment and brain IRS-1 inhibition induced by Alzheimer's $\beta$-amyloid oligomers in mice and monkeys. Cell Metab. 18, 831-843. doi: 10.1016/j.cmet. 2013.11.002

Lourenco, M. V., and Ledo, J. H. (2013). Targeting Alzheimer's pathology through PPAR $\gamma$ signaling: modulation of microglial function. J. Neurosci. 33, 5083-5084. doi: 10.1523/JNEUROSCI.0172-13.2013

Ma, T., Trinh, M. A., Wexler, A. J., Bourbon, C., Gatti, E., Pierre, P., et al. (2013). Suppression of eIF2 $\alpha$ kinases alleviates Alzheimer's disease-related plasticity and memory deficits. Nat. Neurosci. 16, 1299-1305. doi: 10.1038/nn.3486

Ma, Q. L., Yang, F., Rosario, E. R., Ubeda, O. J., Beech, W., Gant, D. J., et al. (2009). $\beta$-amyloid oligomers induce phosphorylation of tau and inactivation of insulin receptor substrate via c-Jun $\mathrm{N}$-terminal kinase signaling: suppression by omega-3 fatty acids and curcumin. J. Neurosci. 29, 9078-9089. doi: 10. 1523/JNEUROSCI.1071-09.2009

Masters, C. L., Simms, G., Weinman, N. A., Multhaup, G., Mcdonald, B. L., and Beyreuther, K. (1985). Amyloid plaque core protein in Alzheimer disease and down syndrome. Proc. Natl. Acad. Sci. U S A 82, 4245-4249. doi: 10.1073/pnas. 82.12 .4245

Matsuzaki, T., Sasaki, K., Tanizaki, Y., Hata, J., Fujimi, K., Matsui, Y., et al. (2010). Insulin resistance is associated with the pathology of Alzheimer disease: the Hisayama Study. Neurology 75, 764-770. doi: 10.1212/wnl.0b013e3181eee25f
Mattson, M. P. (2008). Hormesis defined. Ageing Res. Rev. 7, 1-7. doi: 10.1016/j. arr.2007.08.007

Mattson, M. P. (2012). Energy intake and exercise as determinants of brain health and vulnerability to injury and disease. Cell Metab. 16, 706-722. doi: 10.1016/j. cmet.2012.08.012

McAlpine, F. E., Lee, J., Harms, A. S., Ruhn, K. A., Blurton-Jones, M., Hong, J., et al. (2009). Inhibition of soluble TNF signaling in a mouse model of Alzheimer's disease prevents pre-plaque amyloid-associated neuropathology. Neurobiol. Dis. 34, 163-177. doi: 10.1016/j.nbd.2009.01.006

Medeiros, R., Prediger, R. D. S., Passos, G. F., Pandolfo, P., Duarte, F. S., Franco, J. L., et al. (2007). Connecting TNF- $\alpha$ signaling pathways to iNOS expression in a mouse model of Alzheimer's disease: relevance for the behavioral and synaptic deficits induced by amyloid- $\beta$ protein. J. Neurosci. 27, 5394-5404. doi: 10. 1523/jneurosci.5047-06.2007

Medinas, D. B., and Hetz, C. (2013). Proteostasis impairment: at the intersection between Alzheimer's disease and diabetes. Cell Metab. 18, 771-772. doi: 10. 1016/j.cmet.2013.11.009

Mitsuda, T., Hayakawa, Y., Itoh, M., Ohta, K., and Nakagawa, T. (2007). ATF4 regulates gamma-secretase activity during amino acid imbalance. Biochem. Biophys. Res. Commun. 352, 722-727. doi: 10.1016/j.bbrc.2006. 11.075

Moloney, A. M., Griffin, R. J., Timmons, S., O'connor, R., Ravid, R., and O'neill, C. (2010). Defects in IGF-1 receptor, insulin receptor and IRS$1 / 2$ in Alzheimer's disease indicate possible resistance to IGF-1 and insulin signalling. Neurobiol. Aging 31, 224-243. doi: 10.1016/j.neurobiolaging.2008. 04.002

Monson, N. L., Ireland, S. J., Ligocki, A. J., Chen, D., Rounds, W. H., Li, M., et al. (2014). Elevated CNS inflammation in patients with preclinical Alzheimer's disease. J. Cereb. Blood Flow Metab. 34, 30-33. doi: 10.1038/jcbfm. 2013.183

Moreno, J. A., Halliday, M., Molloy, C., Radford, H., Verity, N., Axten, J. M., et al. (2013). Oral treatment targeting the unfolded protein response prevents neurodegeneration and clinical disease in prion-infected mice. Sci. Transl. Med. 5:206ra138. doi: 10.1126/scitranslmed.3006767

Moreno, J. A., Radford, H., Peretti, D., Steinert, J. R., Verity, N., Martin, M. G., et al. (2012). Sustained translational repression by eIF $2 \alpha-\mathrm{P}$ mediates prion neurodegeneration. Nature 485, 507-511. doi: 10.1038/nature11058

Morris, G. P., Clark, I. A., and Vissel, B. (2014). Inconsistencies and controversies surrounding the amyloid hypothesis of Alzheimer's disease. Acta Neuropathol. Commun. 2:135. doi: 10.1186/s40478-014-0135-5

Mouton-Liger, F., Paquet, C., Dumurgier, J., Bouras, C., Pradier, L., Gray, F., et al. (2012a). Oxidative stress increases BACE1 protein levels through activation of the PKR-eIF2 $\alpha$ pathway. Biochimica et Biophysica Acta (BBA) - Mol. Basis Dis. 1822, 885-896. doi: 10.1016/j.bbadis.2012.01.009

Mouton-Liger, F., Paquet, C., Dumurgier, J., Lapalus, P., Gray, F., Laplanche, J.-L., et al. (2012b). Increased cerebrospinal fluid levels of double-stranded RNA-dependent protein kinase in Alzheimer's disease. Biol. Psychiatry 71, 829-835. doi: 10.1016/j.biopsych.2011.11.031

Mucke, L., and Selkoe, D. J. (2012). Neurotoxicity of amyloid-beta protein: synaptic and network dysfunction. Cold Spring Harb. Perspect. Med. 2:a006338. doi: 10.1101/cshperspect.a006338

Nakamura, T., Kunz, R. C., Zhang, C., Kimura, T., Yuan, C. L., Baccaro, B., et al. (2015). A critical role for PKR complexes with TRBP in immunometabolic regulation and eIF2alpha phosphorylation in obesity. Cell Rep. 11, 295-307. doi: 10.1016/j.celrep.2015.03.021

Nisticò, R., Cavallucci, V., Piccinin, S., Macrì, S., Pignatelli, M., Mehdawy, B., et al. (2012). Insulin receptor $\beta$-subunit haploinsufficiency impairs hippocampal late-phase LTP and recognition memory. Neuromolecular Med. 14, 262-269. doi: 10.1007/s12017-012-8184-z.

O’Connor, T., Sadleir, K. R., Maus, E., Velliquette, R. A., Zhao, J., Cole, S. L., et al. (2008). Phosphorylation of the translation initiation factor eIF $2 \alpha$ increases BACE1 levels and promotes amyloidogenesis. Neuron 60, 988-1009. doi: 10 . 1016/j.neuron.2008.10.047

O’Neill, C. (2013). PI3-kinase/Akt/mTOR signaling: impaired on/off switches in aging, cognitive decline and Alzheimer's disease. Exp. Gerontol. 48, 647-653. doi: 10.1016/j.exger.2013.02.025

Ott, A., Stolk, R. P., Hofman, A., Van Harskamp, F., Grobbee, D. E., and Breteler, M. M. B. (1996). Association of diabetes mellitus and dementia: the rotterdam study. Diabetologia 39, 1392-1397. doi: 10.1007/s001250050588 
Ott, A., Stolk, R. P., Van Harskamp, F., Pols, H. A. P., Hofman, A., and Breteler, M. M. B. (1999). Diabetes mellitus and the risk of dementia: the rotterdam study. Neurology 53, 1937-1937. doi: 10.1212/wnl.53.9.1937

Ounallah-Saad, H., Sharma, V., Edry, E., and Rosenblum, K. (2014). Genetic or pharmacological reduction of perk enhances cortical-dependent taste learning. J. Neurosci. 34, 14624-14632. doi: 10.1523/jneurosci.2117-14.2014

Ozcan, U., Cao, Q., Yilmaz, E., Lee, A. H., Iwakoshi, N. N., Ozdelen, E., et al. (2004). Endoplasmic reticulum stress links obesity, insulin action and type 2 diabetes. Science 306, 457-461. doi: 10.1126/science.1103160

Ozcan, U., Yilmaz, E., Ozcan, L., Furuhashi, M., Vaillancourt, E., Smith, R. O., et al. (2006). Chemical chaperones reduce ER stress and restore glucose homeostasis in a mouse model of type 2 diabetes. Science 313, 1137-1140. doi: 10.1126/science.1128294

Pan, X. D., Zhu, Y. G., Lin, N., Zhang, J., Ye, Q. Y., Huang, H. P., et al. (2011). Microglial phagocytosis induced by fibrillar beta-amyloid is attenuated by oligomeric beta-amyloid: implications for Alzheimer's disease. Mol. Neurodegener. 6:45. doi: 10.1186/1750-1326-6-45

Paquet, C., Mouton-Liger, F., Meurs, E. F., Mazot, P., Bouras, C., Pradier, L., et al. (2011). The PKR activator PACT is induced by $\mathrm{A} \beta$ : involvement in Alzheimer's disease. Brain Pathol. 22, 219-229. doi: 10.1111/j.1750-3639.2011.00520.x.

Parajuli, B., Sonobe, Y., Horiuchi, H., Takeuchi, H., Mizuno, T., and Suzumura, A. (2013). Oligomeric amyloid beta induces IL-1beta processing via production of ROS: implication in Alzheimer's disease. Cell Death Dis. 4:e975. doi: 10. 1038/cddis.2013.503

Prince, M., Bryce, R., Albanese, E., Wimo, A., Ribeiro, W., and Ferri, C. P. (2013). The global prevalence of dementia: a systematic review and metaanalysis. Alzheimers Dement. 9, 63.e2-75.e2. doi: 10.1016/j.jalz.2012.11.007

Rajasethupathy, P., Antonov, I., Sheridan, R., Frey, S., Sander, C., Tuschl, T., et al. (2012). A role for neuronal pirnas in the epigenetic control of memory-related synaptic plasticity. Cell 149, 693-707. doi: 10.1016/j.cell.2012.02.057

Raven, J. F., and Koromilas, A. E. (2008). PERK and PKR: old kinases learn new tricks. Cell Cycle 7, 1146-1150. doi: 10.4161/cc.7.9.5811

Ricobaraza, A., Cuadrado-Tejedor, M., Marco, S., Pérez-Otaño, I., and GarcíaOsta, A. (2010). Phenylbutyrate rescues dendritic spine loss associated with memory deficits in a mouse model of Alzheimer disease. Hippocampus 22, 1040-1050. doi: 10.1002/hipo.20883

Ricobaraza, A., Cuadrado-Tejedor, M., Perez-Mediavilla, A., Frechilla, D., Del Rio, J., and Garcia-Osta, A. (2009). Phenylbutyrate ameliorates cognitive deficit and reduces tau pathology in an Alzheimer's disease mouse model. Neuropsychopharmacology 34, 1721-1732. doi: 10.1038/npp.2008.229

Roffé, M., Hajj, G. N., Azevedo, H. F., Alves, V. S., and Castilho, B. A. (2013). IMPACT is a developmentally regulated protein in neurons that opposes the eukaryotic initiation factor 2alpha kinase GCN2 in the modulation of neurite outgrowth. J. Biol. Chem. 288, 10860-10869. doi: 10.1074/jbc.m113.461970

Rossato, J. I., Bevilaqua, L. R., Myskiw, J. C., Medina, J. H., Izquierdo, I., and Cammarota, M. (2007). On the role of hippocampal protein synthesis in the consolidation and reconsolidation of object recognition memory. Learn. Mem. 14, 36-46. doi: 10.1101/lm.422607

Schubert, M., Gautam, D., Surjo, D., Ueki, K., Baudler, S., Schubert, D., et al. (2004). Role for neuronal insulin resistance in neurodegenerative diseases. Proc. Natl. Acad. Sci. U S A 101, 3100-3105. doi: 10.1073/pnas.0308724101

Segev, Y., Michaelson, D. M., and Rosenblum, K. (2012). ApoE $\epsilon 4$ is associated with eIF2 $\alpha$ phosphorylation and impaired learning in young mice. Neurobiol. Aging 34, 863-872. doi: 10.1016/j.neurobiolaging.2012.06.020

Selkoe, D. J. (2002). Alzheimer's disease is a synaptic failure. Science 298, 789-791. doi: 10.1126/science.1074069

Sondag, C. M., Dhawan, G., and Combs, C. K. (2009). Beta amyloid oligomers and fibrils stimulate differential activation of primary microglia. $J$. Neuroinflammation 6:1. doi: 10.1186/1742-2094-6-1
Steen, E., Terry, B. M., Rivera, E. J., Cannon, J. L., Neely, T. R., Tavares, R., et al. (2005). Impaired insulin and insulin-like growth factor expression and signaling mechanisms in Alzheimer's disease - is this type 3 diabetes? J. Alzheimers Dis. 7, 63-80.

Stern, E., Chinnakkaruppan, A., David, O., Sonenberg, N., and Rosenblum, K. (2013). Blocking the eIF2 $\alpha$ kinase (PKR) enhances positive and negative forms of cortex-dependent taste memory. J. Neurosci. 33, 2517-2525. doi: 10. 1523/JNEUROSCI.2322-12.2013

Talbot, K., Wang, H., Kazi, H., Han, L., Bakshi, K. P., Stucky, A., et al. (2012). Demonstrated brain insulin resistance in Alzheimer's disease patients is associated with IGF-1 resistance, IRS-1 dysregulation and cognitive decline. J. Clin. Invest. 122, 1316-1338. doi: 10.1172/JCI59903

Vallerie, S. N., and Hotamisligil, G. S. (2010). The role of JNK proteins in metabolism. Sci. Transl. Med. 2:60rv65. doi: 10.1126/scitranslmed.3001007

van der Harg, J. M., Nölle, A., Zwart, R., Boerema, A. S., Van Haastert, E. S., Strijkstra, A. M., et al. (2014). The unfolded protein response mediates reversible tau phosphorylation induced by metabolic stress. Cell Death Dis. 5:e1393. doi: 10.1038/cddis.2014.354

Viola, K. L., and Klein, W. L. (2015). Amyloid beta oligomers in Alzheimer's disease pathogenesis, treatment and diagnosis. Acta Neuropathol. 129, 183-206. doi: 10.1016/j.bpj.2014.11.1128

Wang, R., Li, J. J., Diao, S., Kwak, Y. D., Liu, L., Zhi, L., et al. (2013). Metabolic stress modulates Alzheimer's beta-secretase gene transcription via SIRT1PPARgamma-PGC-1 in neurons. Cell Metab. 17, 685-694. doi: 10.1016/j.cmet. 2013.03.016

Wiley, J. C., Pettan-Brewer, C., and Ladiges, W. C. (2011). Phenylbutyric acid reduces amyloid plaques and rescues cognitive behavior in $\mathrm{AD}$ transgenic mice. Aging Cell 10, 418-428. doi: 10.1111/j.1474-9726.2011.00680.x

Xia, W., Yang, T., Shankar, G. M., Smith, I. M., Shen, Y., Walsh, D., et al. (2009). A specific enzyme-linked immunosorbent assay for measuring $\beta$-amyloid protein oligomers in human plasma and brain tissue of patients with Alzheimer disease. Arch. Neurol. 66, 190-199. doi: 10.1001/archneurol.2008.565

Yamanaka, M., Ishikawa, T., Griep, A., Axt, D., Kummer, M. P., and Heneka, M. T. (2012). PPAR $\gamma / R X R \alpha$-induced and CD36-mediated microglial amyloid- $\beta$ phagocytosis results in cognitive improvement in amyloid precursor protein/presenilin 1 mice. J. Neurosci. 32, 17321-17331. doi: 10. 1523/JNEUROSCI.1569-12.2012

Yang, Y. M., Shang, D. S., Zhao, W. D., Fang, W. G., and Chen, Y. H. (2013). Microglial TNF-alpha-dependent elevation of MHC class I expression on brain endothelium induced by amyloid-beta promotes $\mathrm{T}$ cell transendothelial migration. Neurochem. Res. 38, 2295-2304. doi: 10.1007/s11064-013-1138-5

Yoon, S. O., Park, D. J., Ryu, J. C., Ozer, H. G., Tep, C., Shin, Y. J., et al. (2012). JNK3 perpetuates metabolic stress induced by A $\beta$ peptides. Neuron 75 , 824-837. doi: 10.3410/f.717965605.793466623

Zhu, P. J., Huang, W., Kalikulov, D., Yoo, J. W., Placzek, A. N., Stoica, L., et al. (2011). Suppression of PKR promotes network excitability and enhanced cognition by interferon- $\gamma$-mediated disinhibition. Cell 147, 1384-1396. doi: 10. 1016/j.cell.2011.11.029

Conflict of Interest Statement: The authors declare that the research was conducted in the absence of any commercial or financial relationships that could be construed as a potential conflict of interest.

Copyright (C) 2015 De Felice and Lourenco. This is an open-access article distributed under the terms of the Creative Commons Attribution License (CC BY). The use, distribution and reproduction in other forums is permitted, provided the original author(s) or licensor are credited and that the original publication in this journal is cited, in accordance with accepted academic practice. No use, distribution or reproduction is permitted which does not comply with these terms. 